\title{
Daniela Pizzagalli, L'amore di Milano (1834-1838)
}

\section{Marco Stupazzoni}

\section{(2) OpenEdition}

\section{Journals}

\section{Edizione digitale}

URL: http://journals.openedition.org/studifrancesi/33431

DOI: 10.4000/studifrancesi.33431

ISSN: 2421-5856

\section{Editore}

Rosenberg \& Sellier

\section{Edizione cartacea}

Data di pubblicazione: 1 décembre 2005

Paginazione: 663

ISSN: 0039-2944

\section{Notizia bibliografica digitale}

Marco Stupazzoni, «Daniela Pizzagalli, L'amore di Milano (1834-1838)», Studi Francesi [Online], 147 (XLX I III) | 2005, online dal 30 novembre 2015, consultato il 18 avril 2021. URL: http://

journals.openedition.org/studifrancesi/33431 ; DOI: https://doi.org/10.4000/studifrancesi.33431

\section{Questo documento è stato generato automaticamente il 18 avril 2021.}

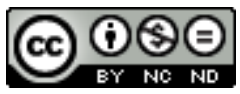

Studi Francesi è distribuita con Licenza Creative Commons Attribuzione - Non commerciale - Non opere derivate 4.0 Internazionale. 


\title{
Daniela Pizzagalli, L'amore di Milano (1834-1838)
}

\author{
Marco Stupazzoni
}

\section{NOTIZIA}

DANiela Pizzagalli, L'amore di Milano (1834-1838), in L'Amica. Clara Maffei e il suo salotto nel Risorgimento, Milano, BUR Saggi, 2004, pp. 16-32.

1 Pubblicato, in prima edizione, nel 1997, questo studio biografico di Daniela Pizzagalli sulla figura di Chiara Maffei - la cui sensibilità culturale la rese promotrice e protagonista di uno tra i più frequentati salotti romantici italiani - trova, in questa rinnovata edizione, la sua felice collocazione nel panorama editoriale del nostro Paese.

Nel capitolo che segnaliamo all'attenzione dei lettori, l'A. considera la galleria delle personalità storiche, politiche e artistiche che furono ospiti illustri del suo salotto dal 1834 (anno di apertura) sino al 1838: tra questi, troviamo segnalati, nel celebre libro delle dediche, Tommaso Grossi e Massimo D’Azeglio, il pittore veneziano Francesco Hayez, Franz Liszt e, non certo ultimo per importanza, Honoré de Balzac, ospite a Milano in occasione del suo secondo soggiorno italiano, nel 1837. La squisita dolcezza che caratterizzò il legame tra lo scrittore francese e la 'piccola Maffei' sono documentate da un certo numero di lettere, tradotte per l'occasione dall'A., nelle quali Balzac non esita a confessare le sue impressioni di viaggio raccolte durante i suoi soggiorni a Milano e a Venezia. Agli amici milanesi, il romanziere dedicò diversi romanzi della Comédie humaine: a Clara Maffei, il racconto La Fausse Maîtresse dove, nota l'A. in conclusione, «la troviamo adombrata nel personaggio della contessa Clémentine, un'esaltazione dell'amicizia» (pp. 31-32). 